\title{
Analysis and Countermeasures of the Translation of Jiangxi Merchant Information from the Perspective of Cultural Communication
}

\author{
Lin Yun ${ }^{1,}$, Wu Jing ${ }^{2, ~ b}$ \\ 1, 2Jiangxi Institute of Economic Administrators, Nanchang, Jiangxi, China, 330088 \\ a46983725@qq.com, b20647795@qq.com
}

Keywords: Cross-culture; Jiangxi merchants; Translation; Strategy

\begin{abstract}
With the gradual advancement of economic globalization, foreign business activities are becoming increasingly frequent in China. Foreign trade is inseparable from business translation, and its development will inevitably lead to an increase in the demand for business translation. With the continuous expansion of business translation industry, many problems have emerged. Translation is not only the transformation of language, but also a cultural transformation. This paper explores strategies to improve translators' information translation of Jiangxi merchant, so as to improve translator's bilingual translation ability and improve their cultural comparison and transformation awareness in translation practice. This paper analyzes the information translation of Jiangxi merchants from the perspective of cultural communication, and on this basis, puts forward the strategies to improve the information translation of Jiangxi merchants.
\end{abstract}

\section{Introduction}

Translation is not just conversion from one language to another language; it involves culture and information transmission between two languages. Culture is vital to translation. With science advancement and economic development, the comprehensive strength of China is gradually increasing. Jiangxi merchants play a significant role in the development of Jiangxi's economy. This paper starts from analysis on Jiangxi merchant information translation from the perspective of cultural transmission, and then puts forward several strategies to improve the information translation of Jiangxi merchants.

\section{Jiangxi merchant culture communication}

Jiangxi merchants are known as merchants who do business in Jiangxi province. Jiangxi business group came into being during the Tang and Song dynasties and developed in the late Yuan and early Ming dynasties. From the middle and late Ming dynasty to Qing dynasty, it flourished. During Ming and Qing dynasty, Jiangxi business group traded in a wide range of areas and almost throughout the country. Because of its outstanding financial status, Jiangxi business group ranked third in the top ten business groups, and had a great impact on China's economy at that time.

\subsection{Background of Jiangxi merchant prosperity}

Plenty of activities of Jiangxi merchant can be found from historical record. A poem written by the famous poet Bai Juyi of the Tang Dynasty mentions that a tea merchant went to Fuliang, a Jiangxi county, to buy tea. It is also recorded that in the Tang Dynasty, a merchant from Nan Chang whose surname was Xie, made a lot of money with his daughter Xie Xiao'e in Anhui Province. Later, Mr. Xie married his daughter to a local person and they continued to trade together. Moreover, Zeng Shuqing, uncle of the great writer Zeng Gong in the Northern Song Dynasty, repeatedly went to Jingdezhen to buy ceramics so as to trade them in the north of Anhui.

There are many reasons why Jiangxi merchant group formed. The first reason is the economic development. Thanks to the southward shift of the economic center and the eastward movement of the political center, the economy in the southern part of the Yangtze River had enjoyed rapid development since the Tang Dynasty. In the Song Dynasty, Jiangxi became the leading region of 
economic development. In addition to meeting the needs of the region, Jiangxi still had a surplus of handicrafts and agricultural products to be supplied to the other provinces. The economic development of Jiangxi provided the prerequisite for the formation of Jiangxi business group. On this basis, Jiangxi merchant started to do business, accumulated capital and formed a business group gradually. The second reason is the benefits of transportation. Since the ancient times, Jiangxi occupies an important position in terms of location and transportation. Jiangxi has formed a complete water and land transportation network, with Poyang Lake as the center; rivers such as Gan River, Fuhe River, Xinjiang River, Xiuhe River and Raohe River as the important parts; the land transportation in the surrounding areas as essential supplement. In particular, the construction of the ancient trail at Mountain Mei (Da Yuling) opened up the golden water trade channel between the Grand Canal, the Yangtze River, the Ganjiang River and the Pearl River, which provided great transportation convenience for the development of Jiangxi business group. The third reason is the population movement. In Chinese history, people in the north have immigrated to the south for three times, and a large number of people poured into Jiangxi every time. In the Northern Song Dynasty, Jiangxi population leaded the country with its 4460,000 people. In the early Yuan Dynasty, the population in Jiangxi accounted for $23 \%$ of the country's population. In the early Ming Dynasty, on the basis of the free flow of the people, the government organized a large-scale immigration. The great migrations of Jiangxi ancestors created a new world in the history of China. The large-scale population movement stimulated the development of commerce and directly led to the development and prosperity of Jiangxi business group.

\subsection{The unique business characteristics of Jiangxi merchants}

Jiangxi merchants have many unique business characteristics.

Jiangxi merchants attach importance to "virtue". First of all, Jiangxi merchants love the motherland and love the people. To serve the country industry as their ideal, they made a great contribution to the development of China's national industry. At the beginning of the foundation of New China, Jiangxi merchants all responded to the government call of and took the initiative in public-private partnerships, making an important contribution to the economic recovery and prosperity of New China. Secondly, Jiangxi merchants abide by the code of ethics and emphasize the justice of contracts. Thirdly, Jiangxi merchants are diligent, simple and honest.

Jiangxi merchants pay more attention to "practical work". To begin with, Jiangxi merchants are good at discovering business opportunities. In the Ming and Qing Dynasties, Jiangxi merchants keenly seized the favorable government policy, and became one of the major business groups at that time. By making full use of opportunity of reform and opening up, Jiangxi merchants became models of successful private entrepreneurs in China. Secondly, Jiangxi merchants have the internal motivation of being unwilling to lag behind and changing the current situation. They do not wait for the others' help but rely on themselves in pursuit of success. Last but not least, Jiangxi merchants are diligent and hard-working. They work hard, gradually turn small businesses into big businesses, and eventually become industry leaders.

Jiangxi merchants focus on "justice and profit." First of all, Jiangxi merchants scrupulously abide by business ethics and market rules. They operate according to law, keep their promises, and never gain profits illegally. Secondly, Jiangxi merchants pay more attention to cooperation. In order to succeed, they always cooperate with each other and help each other. Furthermore, Jiangxi merchants have been keen on charity in all ages, which provides a positive contribution to local and national charity.

\section{Analysis on improving information translation of Jiangxi merchants}

\subsection{Cultural difference analysis in the information translation of Jiangxi merchants}

The concept of culture was proposed by German scholars in the 20th century. For a long time, people have difference views on the understanding and definition of culture. Up to now,there are more than 260 definitions on culture in the world. According to Eugene A Nida's study, the cultural 
elements in language can be summarized into five kinds: material culture, ecological culture, social culture, religious culture and language culture. The root causes of cultural differences are mainly in the following aspects:

The first is the differences of regional ecological environments. Cultural differences are closely related to the heterogeneity of regional human environment. The geographical environment is different from the ecological environment, and the material culture is also different from the ecological culture. Culture is supported by material, and the characters in different environments created by the author reflect the value orientation and aesthetic awareness of the creator.

The second is the difference in the way of thinking. Thinking creates language. Different ways of thinking lead to different linguistic cultures and social culture. Because of the differences in the ways of thinking between China and the west, the differences of linguistic cultures and social cultures between Chinese and Western languages are obvious. Chinese way of thinking is indicated as screw-type, which is good at hovering in the process of language expression, and ultimately expresses the key content. The westerners are different; their way of thinking is straight line. They speak straightforwardly with clear logic. They put key content in front of the expression process, while the minor parts come to the end. The differences are indicated in the sentence structure. Chinese sentences mostly contain parataxis, it omits associated word between sentences, logic relations is understood by context, while English sentences are mostly hypotaxis, the logic relations between sentences or paragraphs are realized by conjunction.

The third is the mental difference in nation. It is agreed that the people of the nation have a common regional life, common language, and a common social community with relatively stable psychological.

\subsection{Principles of cultural difference analysis in information translation of Jiangxi merchants}

Firstly, business discourse should be the center. Discourse is usually composed of several sentences, which means segment of expressing complete meanings in designated context. In the translation process, translation of business discourse converts the focus of smooth translation from letter to word into segment with complete meanings. In order to achieve translation target in business discourse and to further the win-win cooperation between business partners, translation of business discourse requires the translator to analyze the context of the whole discourse and the target of discourse in the first step.

Secondly, cohesion and coherence are used as measures of the standard. In terms of discourse level, there is a great difference in cohesion and coherence between Chinese and English. There are two main types of cohesive measures: lexical cohesion and grammatical cohesion.

Thirdly, cross-culture communication is taken as the target. Business translation is an indispensable part of the smooth development of international trade. Its essence is cross-cultural communication. Due to the characteristics of intercultural communication, it focuses more on the application effects of intercultural communication.

In the course of business translation, translators should not only consider the different characteristics of Chinese and foreign languages, but should also pay attention to the different cultural characteristics of the two languages, so as to achieve the goal of cross-cultural communication by conforming to the accepted expressions of readers.

\section{Strategies of improving information translation of Jiangxi merchants}

\subsection{Grasp cognitive skills of enhancing translation}

Successful translation means translation validity. To improve translation validity, it is necessary to avoid the divergence between the target language and the primitive language to the maximum extent, and to convey the communicative intention of the primitive language. Good translators are also critical thinkers. The cognitive skills in translation include the following: interpretation, analysis, evaluation, inference, explanation and self-regulation (Figure 1). These six skills are the core of cognitive skills in translation. 


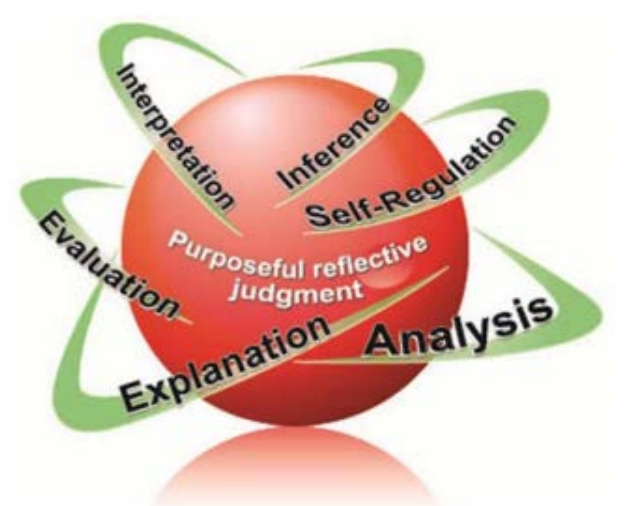

Figure 1 The core Cognitive Skills

Doing well in logic language arrangement and application in translation can pave solid base to further enhance cognitive skills in information translation of Jiangxi merchants, which is also one of the strategies of improving information translation of Jiangxi merchants.

\subsection{Enhance cross-culture awareness consciously}

Translation is the important media to spread culture, but sometimes cultural information will become lost or out of shape in the translation process. The enhancement of cross-cultural awareness will effectively prevent this phenomenon. Conflict and default in cultural schema are the main obstacles of cultural translation, and cause cultural misunderstandings. The main reason is that translators do not understand cross-culture knowledge; it is caused by interlinear translation. Smoothly completing cross-culture communication is the final target of business discourse translation. In the process of translation, when choosing and applying translation strategies, translators should not only pay attention to function comparison of the original text and language form of translation, but should also notify cultural adaptation in deep level. Only by understanding cultural difference of Chinese and English language can the translation realize the dynamic adaptation of the cultural context and the cultural context of the original, and finally achieve the purpose of business communication.

\subsection{Make translation aim clear}

The information text pattern and translation aim of Jiangxi merchant determine translation strategies. The purpose of business translation is to carry out business activities smoothly, so it is necessary to measure the success or failure of business translation in accordance with the effectiveness of business communication. Successful intercultural communication is a kind of compromise, which seeks the intersection under the effect of original language culture and target language field. In another words, it is necessary to achieve concordance of original language culture and target language culture, and to realize the horizon fusion between the writers, the translators and the readers. Therefore, in order to achieve communication validity, naturalization strategy should be adopted to deal with cultural information in business text. Remedy measures such as literal translation, notes etc should be taken when default information is encountered.

\subsection{Obey pragmatic principles}

Pragmatic principles mainly include politeness principle, cooperative principle, and speech act theory etc. The politeness principle requires the translators to have obvious differences in the way of expressing their politeness in Chinese and English. The cooperative principle makes regulation on translation in terms of quality, quantity, relevance and manner. The speech act theory requires translators explore its implication through language and words, so that it adopts direct or implicit way structure to convey translation with the same implication. In order to achieve social pragmatic effect, these principles are the factors that must be taken into consideration in business discourse translation. 


\section{Conclusions}

Business translation is a cultural activity that conveys the information expressed by a language in another language. It is not only a language process, but also an intercultural communication activity. The study of cultural information, especially the study of implied cultural information, should be an important part of the study of business translation.

How to spread Jiangxi merchant culture and make it move to the world, and thus become the wealth of the world, is still a problem that needs to be solved. This paper explores strategies to improve Jiangxi merchant information translation, in order to improve translators' bilingual translation ability and enhance their cultural comparison and transformation awareness in translation practice. Culture has the character of ethnicity, inheritance and compatibility. Cultural differences are determined by the ethnicity and inheritance of culture, and compatibility of culture provides the possibility for cross culture. Business translation usually has a strong target, which requires translators to be familiar with cultural differences and adopt proper cultural information processing strategy, so as to fully reflect the effectiveness of intercultural communication.

\section{Acknowledgements}

This article is part result of the research on 2017 Jiangxi Province Social Science Planning Project: Countermeasures of Jiangxi "Internet+" Community Home Care Service Platform Construction (project code: 17ZK30)

\section{References}

[1] Zhang Zhihua. Research on Business English Translation under Perspective of Cross-culture [J]. Journal of Lanzhou Institute of Education, 2014, 08:146-147+161.

[2] Kang Juanni, Hao Wenjuan. Pragmatic Analysis on Public Signs Translation Based on Relevance Theory Perspective [J]. Journal of Changchun University of Technology (social science edition), 2013, 03:76-78.

[3] Qian Chunhua. Analysis on Component Element of Translation Ability and Its Driving Ability [J]. Foreign Language World, 2012, 03:59-65.

[4] Yang Aimei. Effect of Cultural Difference on Business English [J]. Chinese Business Theory, 2017, 28:128-129.

[5] Li Chuijia. Thematic Theory, Thematic Progression Pattern and Translation [J]. Journal of (social science), 2006, 04:133-135. 